\title{
Correction to: Loneliness Mediates the Relationship Between Pain During Intercourse and Depressive Symptoms Among Young Women
}

\author{
Madison E. Stout ${ }^{1} \cdot$ Samantha M. Meints ${ }^{1} \cdot$ Adam T. Hirsh $^{1}$
}

Published online: 9 May 2018

(c) Springer Science+Business Media, LLC, part of Springer Nature 2018

\section{Correction to: Arch Sex Behav \\ https://doi.org/10.1007/s10508-017-1138-7}

Due to an oversight on the authors' part, the original article was published without an Acknowledgements section. The correct Acknowledgements text is given below:

Acknowledgements This work was supported in part by the National Institutes of Health under Award Number T32 AR055885 to Samantha Meints.

The original article can be found online at https://doi.org/10.1007/ s10508-017-1138-7.

Adam T. Hirsh

athirsh@iupui.edu

1 Department of Psychology, Indiana University-Purdue

University at Indianapolis, $402 \mathrm{~N}$ Blackford St.,

Indianapolis, IN 46202, USA 